rapid $\mathrm{T}$ cell activation and tolerance by systemic presentation of an orally administered antigen. Immunity 8, 667-673 (1998).

17. Crawford, F., Kozono, H., White, J., Marrack, P. \& Kappler, J.W. Detection of antigenspecific T cells with multivalent soluble class II MHC covalent peptide complexes. Immunity 8, 675-682 (1998).

18. Kearney, E.R., Pape, K.A., Loh, D.Y. \& Jenkins, M.K. Visualization of peptide specific cell immunity and peripheral tolerance induction in vivo. Immunity 1, 327-339 (1994).

19. Schönrich, G. et al. Down-regulation of $T$ cell receptors on self-reactive $T$ cells as a novel mechanism for extrathymic tolerance induction. Cell 65, 293-304 (1991).

20. Chiocchetti, A., Tolosano, E., Hirsch, E., Silengo, L. \& Altruda, F. Green fluorescent protein as a reporter of gene expression in transgenic mice. Biochim. Biophys. Acta 1352, 193-202 (1997)

21. Ebert, O. et al. Lymphocyte apoptosis: Induction by gene transfer techniques. Gene Ther. 4, 296-302 (1997).

22. Kasid, A. et al. Human gene transfer: Characterization of human tumor infiltrating lymphocytes as vehicles for retroviral-mediated gene tranfer in man. Proc. Natl. Acad. Sci. USA 87, 473-477 (1990).

23. Woffendin, C. et al. Nonviral and viral delivery of a human immunodeficiency virus protective gene into primary human T cells. Proc. Natl. Acad. Sci. USA 91, 11581-11585 (1994)

24. Bunnell, B.A., Muul, L.M., Donahue, R.E., Blaese, R.M. \& Morgan, R.A. Highefficiency retroviral-mediated gene transfer into human and nonhuman primate peripheral blood lymphocytes. Proc. Natl. Acad. Sci. USA 92, 7739-7743 (1995).

25. Rudoll, $T$. et al. High efficiency retroviral vector mediated gene transfer into human peripheral blood CD4+ T lymphocytes. Gene Ther. 3, 695-705 (1996).

26. Agarwal, M. et al. Scaffold attachment region-mediated enhancement of retroviral vector. J. Virol. 72, 3720-3728 (1998).

27. Quinn, E.R., Lum, L.G. \& Trevor, K.T. T cell activation modulates retrovirus-mediated gene expression. Hum. Gene Ther. 9, 1457-1467 (1998).

28. Qin, L. et al. Promoter attenuation in gene therapy: Interferon- $\gamma$ and tumor necrosis factor- $\alpha$ inhibit transgene expression. Hum. Gene Ther. 8, 2019-2029 (1997).

29. Pette, M. et al. Myelin basic protein-specific T lymphocyte lines from MS patients and healthy individuals. N eurology 40, 1770-1776 (1990).

30. Miller, A.D. \& Rosman, G. Improved retroviral vectors for gene transfer and expression. BioTechniques 7, 980-990 (1989).

31. Markowitz, D., Goff, S. \& Bank, A. A safe packaging line for gene transfer: Separating viral genes on two different plasmids. J. Virol. 62, 1120-1124 (1988).

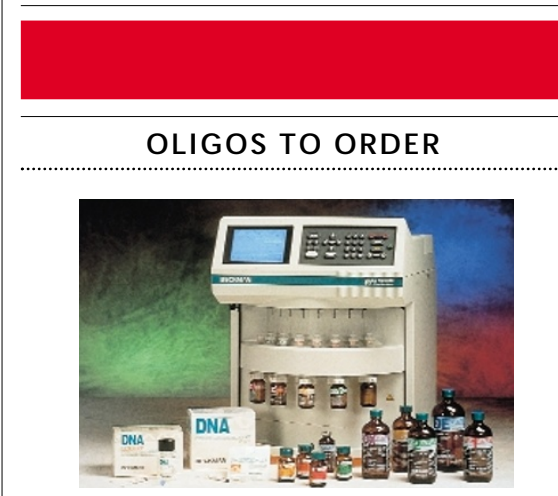

BOSS software for the Oligo 1000M DNA synthesizer.

Beckman has a new oligo sequence server software product for its Oligo 1000M DNA synthesizer. BOSS, which stands for Beckman oligo sequence server, software is intended for core facilities that produce oligos for other labs. It downloads text sequence information into the instrument, for order entry and billing information. It also serves as a reference database and synthesis log book, and will interact with the Oligo 5 primer design program.

Reader Service No. 89

Tel. (+1) 714-871-4848

Fax (+1) 714-773-8186

\section{GONG WITH THE FLOW}

As part of a new worldwide strategic alliance, Dako will market flow cytometer analyzers and sorters defined and specified by Dako and manufactured by PARTEC. A major focus will be on features of volumetric absolute counting without need for additional particles, full walk-away sample preparation/introduction automation, modular upgradability and a built-in Windows 95/98 NT-based computer system for automated data acquisition and analysis.

Reader Service No. 90

Tel. (+45) 44-85-95-00

Fax (+45) 44-85-95-95

\title{
ON THE MARKET
}

\section{TURNING DATA INTO KNOWLEDGE}

GeneSpring 2.1 from Silicon Genetics is an analysis and visualization package designed specifically for genomic expression analysis. The program is compatible with both MicroArray and Affymetrix systems. Version 2.1 includes new features such as easy data import via the company's wizard, enhanced overlay and tree-building capabilities and is Maccompatible.

Reader Service No. 91

Tel. (+1) 650-591-4459

Fax (+1) 650-591-5574

Incyte Pharmaceuticals and Oxford GlycoSciences recently announced the launch of new proteomics database products and the release of a new protein analysis software package called LifeProt. Together, the databases and software are designed to speed up the dis covery and selection of new targets and optimization of lead compounds. This combined proteomics and genomic technology mines data from proteins found in normal, diseased and medically treated tissue samples. The LifeProt software provides tools for seamless integration, data visualization and mining of protein expression data to identify and validate new drug targets.

Reader Service No. 92

Tel. (+1) 650-855-0555

Fax $(+1)$ 650-855-0572

Oxford Molecular has a new version of its $\mathrm{MacVector}$ sequence analysis software program for the Mac. MacVector 6.5 contains several enhancements, including user-defined primer testing, expanded protein tools, flexible property profiles and composition analyses, and new graphics features. Clustal W multiple sequence alignments now include dendrogram output and can be printed in color. MacVector files can be exported in GCG format for use with the Wisconsin Package or read by Oxford Molecular's OMIGA for Windows, making it easy for users to collaborate with colleagues using other platforms.

Reader Service No. 93

Tel. (+44) (0) 1865-784600 (Europe)

Tel. (+1) 408-879-6300 (USA)

\section{IMPROVING YOUR IMAGE}

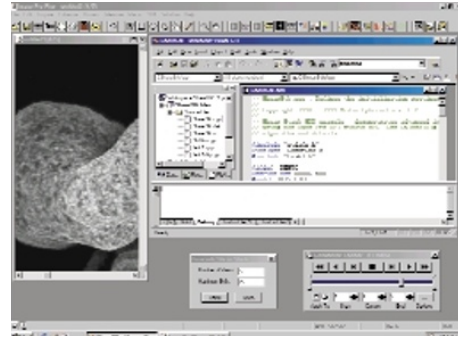

Software development kit 4.0 for Image-Pro Plus-a programming toolkit for imaging applications.

In May, Media Cybernetics announced the release of SDK version 4.0. - a software development kit for Image-Pro Plus. The SDK can be downloaded for free from the company's web site (www.mediacy.com) by Image-Pro Plus 4.0 customers. Unlike many other programming toolkits, the company says its SDK offers a host environment that can be easily and quickly customized to solve specific imaging applications, without needing to start from scratch. It includes a powerful plug-in wizard that can automatically generate an entire $\mathrm{C}++$ project, including source code, resource file and project file. Additionally, it can compile and link with Image-Pro Plus with little or no effort, says the company. Another aspect of the Image-Pro 
SDK is the ease with which users can develop custom plug-ins (written in $C$, $\mathrm{C}+$ /MFC, Visual Basic or Java/J+H) and add them into existing Image-Pro Plus menus and toolbars.

Reader Service No. 94

Tel. (+1) 301-495-3305

Fax (+1) 301-495-5964

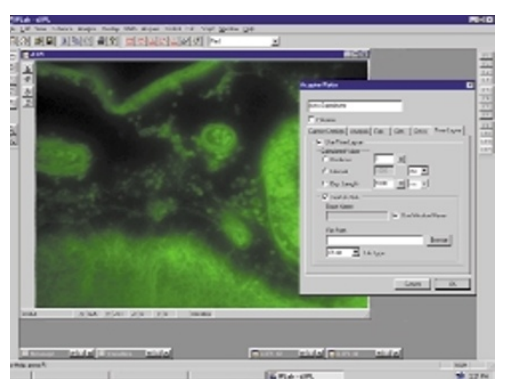

New time-lapse feature allows researchers to capture and view intracellular events as they occur over time.

Scanalytics, a subsidiary of CSP, is now shipping updated versions of its IPLab software, IPLab/Mac V3.2.4 and IPLab/Win v2.4. Available for M acintosh, Windows 95/98 and NT, IPLab software provides scientific image acquisition, visualization, analysis and laboratory automation in a single package. These re leases include a new time-lapse acquire feature that allows scientists to capture and view intracellular events as they occur over a period of time. This feature is designed for easy and accurate time-lapse image data acquisition, and is specially equipped with five separate device-independent scripts for control of external microscopehardware, such asfilter wheels and shutters. Applications of time-lapse imaging include GFP techniques, which study fluorescence in living specimens.

Reader Service No. 95

Tel. (+1) 703-208-2230

Fax (+1) 703-208-1960

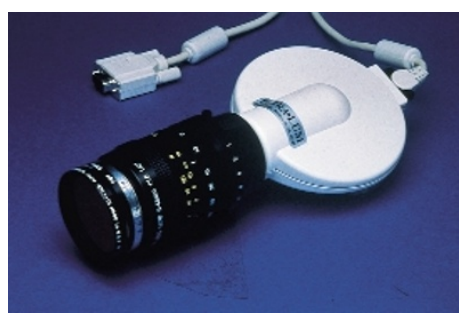

DigiPix digital camera for gel documentation allows viewing of live images before capture.

DigiPix is the new digital camera for gel documentation and image analysis from Ultra-Lum. The camera features over 1.2-million pixel resolution, 24-bit color or monochrome imaging, and a $\mathrm{PCl}$ or PCMCIA card interface to capture images directly on a computer. The $C$-mount on the camera provides flexibility and users have the option of a 6:1 manual zoom, motorized zoom or fixed-focus lens. Viewing live images before capture with the Digi Pix digital camera viewfinder eliminates guesswork when taking pictures of gels. Viewfinder tool bars allow adjustment of brightness, contrast, picture position and pixel resolution. The TWAIN driver enables image acquisition directly into analysis software. (Software for 1D, $2 \mathrm{D}, \mathrm{RFLP}$ and sequence analysis is available from the company.)

Reader Service No. 96

Tel. (+1) 562-529-5959

Fax (+1) 562-529-5950

\section{NET NEWS}

Last month, Lexicon Genetics launched its subscription Internet program that enables commercial and academic/nonprofit institutions to access OmniBank, the company's proprietary genomics library and database. Through the company's web site at www.lexgen.com, subscribers can reach 50,000 mouse clones, which, Lexicon claims, represents the largest collection of knockout mouse embryonic stem cells and gene sequence information. The company says that such resources should provide valuable predictive information on the action of potential therapeutic drug candidates and the validity of their targets.

Reader Service No. 97

Tel. (+1) 281-364-0100

Fax (+1) 281-364-0155

\section{MONITORING ULTRASOUND}

UltraVox for Windows is Noldus Information Technology's system for automatic monitoring of ultrasonic vocalizations. Within the field of neuroscience, ultrasonic utterances are seen as a valuable measure for anxiety, motivational state, and drug withdrawal. By providing flexible acquisition settings, real-time visualization of the filtering process, descriptive statistics and easy export and integration, UltraVox for Windows allows neurobiologists, behavioral pharmacologists and neurotoxicologists to detect and analyze ultrasound the way they wish. UltraVox serves as an acoustical event recorder, automatically monitoring the occurrence of vocalizations within a user-defined frequency band. To achieve this, it combines an ultrasound detector, an audio filter and data acquisition software.

Reader Service No. 98

Tel. (+31) (0) 317-497677

Fax (+31) (0) 317-424496

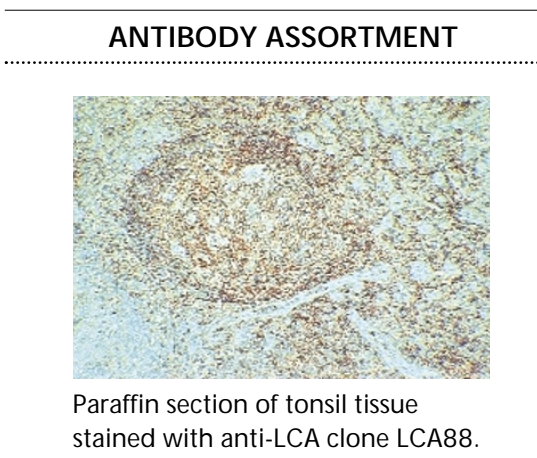

BioGenex Laboratories offers a monoclonal antibody to leukocyte common antigen (LCA88), which reacts specifically with CD45 (LCA) in formalin-fixed, paraffin-embedded tissue sections. CD45 is a transmembrane protein tyrosine phosphatase. The LCA family includes a group of proteins present on all mature $B$ and $T$ lymphocytes, thymocytes, macrophages, spleen, lymph node, chronic Iymphatic leukemia cells, bone marrow, thymus and granulocytes. It is absent from brain, kidney, liver, heart, erythrocytes, platelets and normal serum. The antibody may be useful in the evaluation of malignant lymphoma and nonlymphoid tumors. Neoplastic B and T cells in leukemia and in non-Hodgkin's lymphoma stain positive and, hence, can be distinguished from sarcomas and carcinomas, according to BioGenex.

Reader Service No. 99

Tel. (+1) 925-275-0550

Fax (+1) 925-275-0580

Dynal has introduced a new Dynabeads product, Pan Mouse IgG, which is designed to work with mouse monoclonal antibodies of any IgG subclass. The human anti-mouse IgG antibody binds mouse monoclonals without inter-species crossreactivity and, due to the Fc specificity, bound monoclonals are efficiently directed towards the target cell-surface antigen. The product is suited for depletion procedures where more than one primary mouse monoclonal antibody is used and which may be of differing IgG subclasses.

Reader Service No. 100

Tel. (+47) 22-06-11-36

Fax (+47) 22-50-70-15

For more details, fill in the reader service card at the back of the journal. 